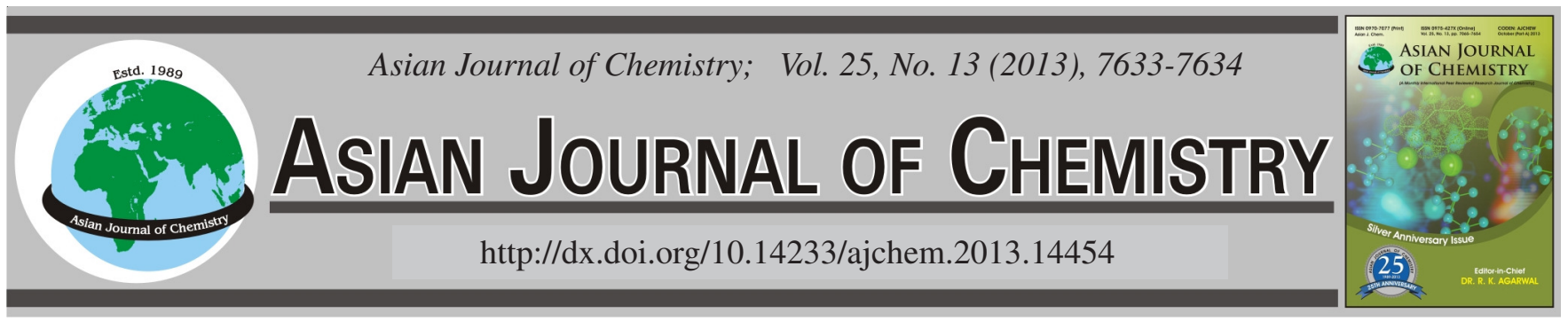

NOTE

\title{
UV-Visible Absorption Study of Four-Substituted Norbornadiene- Quadricyclane System Through DFT Calculations
}

\section{EdJLALI ${ }^{1, *}$ and E. Vessally ${ }^{2}$}

${ }^{1}$ Department of Chemistry, Tabriz Branch, Islamic Azad University, Tabriz, Iran

${ }^{2}$ Department of Chemistry, Miyaneh Branch, Islamic Azad University, Miyaneh, Iran

*Corresponding author: E-mail: 1_edjlali@iaut.ac.ir

UV-visible absorption studies of norbornadiene $\left(\mathbf{1}_{\mathbf{X}}\right)$ /quadricyclane $\left(\mathbf{2}_{\mathbf{X}}\right)$ system were carried out by density functional theory (DFT), method using 6-311++G** basis set of the GAUSSIAN 98 program. The DFT calculations indicate that the solar absorption bands of norbornadiene were shifted to the visible spectrum region through the electron withdrawing substituents more than through electron donating substituents.

Key Words: UV-visible absorption, Norbornadiene, Quadricyclane, Electron donating, Electron withdrawing.

Photoisomerization of norbornadiene (1) to quadricyclane (2) has been considered as an effective way to store solar energy $^{1-3}$. In this reaction, the energy stored in one mole of $\mathbf{2}$ is about $89 \mathrm{~kJ}$ due to its highly-strained structure. The stored energy can be released through the inverse reactions. Compound $\mathbf{2}$ could be considered as a potential high-energy density liquid fuel for the replacement of current fossil fuels. In continuation of our reports ${ }^{3-6}$, in this work UV-visible absorption study of four-substituted norbornadiene-quadricyclane system was carried out through DFT calculations.

Full geometry optimizations of norbornadiene $\left(\mathbf{1}_{\mathbf{X}}\right)$ /quadricyclane $\left(\mathbf{2}_{\mathbf{X}}\right)$ system were carried out by density functional theory (DFT), method using 6-311++G** basis set of the GAUSSIAN 98 program $^{7-9}$ (Scheme-I). To find a global minimum on a specific surface, all possible conformations of the given species were examined through scanning the specific dihedral angles at B3LYP/6-311++G** level. All calculations were carried out for gas phase at $298 \mathrm{~K}$ and $1 \mathrm{~atm}$.

In this work, we studied the photochemical energy storage of $\mathbf{1}_{\mathbf{X}} / \mathbf{2}_{\mathbf{X}}\left(\mathrm{X}=-\mathrm{NH}_{2},-\mathrm{OH},-\mathrm{CO}_{2} \mathrm{H},-\mathrm{CONH}_{2}\right.$ and $\left.\mathrm{CN}\right)$ system with pull-pull, push-push and pull-push substituents (SchemeI). We found that the carbon atoms, $\mathrm{C}_{2}, \mathrm{C}_{3}, \mathrm{C}_{5}$ and $\mathrm{C}_{6}$ were more sensetive to substitutent effect than $\mathrm{C}_{1}, \mathrm{C}_{4}$ and/or $\mathrm{C}_{7}{ }^{3,4}$. Thus, we selected the carbon atoms $\mathrm{C}_{2}, \mathrm{C}_{3}, \mathrm{C}_{5}$ and $\mathrm{C}_{6}$ to investigation of UV-visible absorption. The thermal energy gaps, $\Delta \mathrm{E}_{(\mathbf{1} \mathbf{x})-(\mathbf{2 x})}$, enthalpy gaps, $\Delta \mathrm{H}_{(\mathbf{1} \mathbf{x})-(\mathbf{2 x})}$ and free energy gaps, $\Delta \mathrm{G}_{(\mathbf{1 x})-(\mathbf{2 x})}$, in $\mathrm{kcal} \mathrm{mol}^{-1}$, between norbornadienes $\left(\mathbf{1}_{\mathbf{X}}\right)$ and their

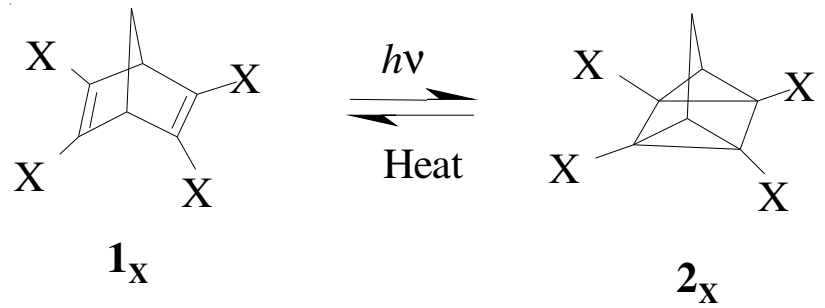

Scheme-I: Norbornadiene $\left(\mathbf{1}_{\mathbf{X}}\right)$ and quadricyclane $\left(\mathbf{2}_{\mathbf{X}}\right)$ where $\mathrm{X}=-\mathrm{CO}_{2} \mathrm{H}$, $-\mathrm{CONH}_{2},-\mathrm{CN},-\mathrm{NO}_{2},-\mathrm{OH}$ and $-\mathrm{NH}_{2}$

corresponding quadricyclanes $\left(\mathbf{2}_{\mathbf{X}}\right)$ have been presented ${ }^{3,4}$. DFT calculations indicated that the Gibbs free energy gaps between $\mathbf{1}_{\mathbf{X}}$ and $\mathbf{2}_{\mathbf{X}}, \Delta \mathrm{G}_{(\mathbf{1 x )}-(\mathbf{2 x})}$, was the least when two electron withdrawing substituents and electron donating substituents (pullpush) were attached at both carbon atoms of the double bond $\mathrm{C}_{2}=\mathrm{C}_{3}$ and $\mathrm{C}_{5}=\mathrm{C}_{6}$, respectively. The $\Delta \mathrm{G}_{(\mathbf{1 x})-(\mathbf{2 x})}$, was the most when four electron donating substituents (push-push) were attached at the double bond $\mathrm{C}_{2}=\mathrm{C}_{3}$ and $\mathrm{C}_{5}=\mathrm{C}_{6}$. However, the $\Delta \mathrm{G}_{(\mathbf{1 x})-(\mathbf{2 x})}$, was increased when the electron withdrawing substituents (pull-pull) were attached at two sides of the double bonds $\mathrm{C}_{2}=\mathrm{C}_{3}$ and $\mathrm{C}_{5}=\mathrm{C}_{6}$.

The excited states of $\mathbf{1}_{\mathbf{X}}$ could be related to their corresponding the UV-visible absorption (Table-1). Despite the importance of achieving the maximum stored solar energy by a chromopher or substituent, the absorption wavelength region was also important which was suitable when was shifted to the visible region. Therefore, the effects of both electron 

PARENTHESIS) FOR OPTIMIZED X-NORBORNADIENES $\left(\mathbf{1}_{\mathrm{x}}\right)$; WHERE $\mathrm{X}=-\mathrm{NO}_{2},-\mathrm{CN},-\mathrm{CONH}_{2},-\mathrm{NH}_{2} \mathrm{AND}-\mathrm{OH}$

\begin{tabular}{lllllll}
\hline (Compound) & & \multicolumn{5}{c}{ Wavelength (intensity) } \\
\hline $\mathbf{1}_{\text {NO2 }}$ & $303.89(0.003)$ & $304.64(0.000)$ & $317.05(0.019)$ & $317.06(0.000)$ & $343.55(0.003)$ & $349.65(0.000)$ \\
$\mathbf{1}_{\text {CONH2 }}$ & $276.97(0.018)$ & $278.07(0.006)$ & $290.45(0.005)$ & $304.80(0.001)$ & $314.82(0.001)$ & $346.57(0.001)$ \\
$\mathbf{1}_{\text {CN }}$ & $221.75(0.717)$ & $239.90(0.066)$ & $243.74(0.000)$ & $246.84(0.000)$ & $304.65(0.007)$ & $325.03(0.000)$ \\
$\mathbf{1}_{\text {OH }}$ & $258.21(0.001)$ & $265.77(0.001)$ & $271.91(0.000)$ & $289.82(0.000)$ & $325.98(0.000)$ & $343.20(0.001)$ \\
$\mathbf{1}_{\text {NH2 }}$ & $310.64(0.003)$ & $325.15(0.010)$ & $342.05(0.002)$ & $366.36(0.000)$ & $413.11(0.001)$ & $433.65(0.015)$ \\
$\mathbf{1}_{\text {CO2H-OH }}$ & $261.40(0.005)$ & $262.20(0.002)$ & $269.05(0.040)$ & $280.10(0.006)$ & $281.42(0.001)$ & $536.79(0.004)$ \\
$\mathbf{1}_{\text {NO2-NH2 }}$ & $301.47(0.007)$ & $323.95(0.018)$ & $343.17(0.002)$ & $355.38(0.043)$ & $472.98(0.013)$ & $568.79(0.053)$ \\
$\mathbf{1}_{\text {CONH2-OH }}$ & $255.92(0.013)$ & $258.51(0.001)$ & $283.43(0.001)$ & $290.36(0.002)$ & $303.89(0.015)$ & $471.43(0.000)$ \\
$\mathbf{1}_{\text {CN-NH2 }}$ & $257.32(0.050)$ & $259.37(0.021)$ & $276.84(0.001)$ & $283.55(0.005)$ & $342.62(0.008)$ & $611.42(0.000)$ \\
\hline
\end{tabular}

withdrawing and electron donating subsituents on the UVvisible absorption wavelength region were investigated on four positions of $\mathbf{1}_{\mathbf{X}}$ ( $\mathrm{X}$ attached at carbons $\mathrm{C}_{2}, \mathrm{C}_{3}, \mathrm{C}_{5}$ and $\mathrm{C}_{6}$ ) (Table$1)$. All the results of the UV-visible absorption wavelength region for both electron withdrawing and electron donating subsituents at carbon atoms $\mathrm{C}_{2}, \mathrm{C}_{3}, \mathrm{C}_{5}$ and $\mathrm{C}_{6}$ of $\mathbf{1}_{\mathbf{x}}$ were tabulated (Table-1).

In general, all the substituents change the spectral band position in the absorption, reflectance, transmittance, or emission spectrum of a molecule to a longer wavelength. Here, the electron donating and withdrawing subsituents were selected for making higher efficiency of the $\mathbf{1}_{\mathbf{X}} / \mathbf{2}_{\mathrm{X}}$ system in the absorption of UV-visible bands. Electron donating subsituents $\left(\mathrm{X}=-\mathrm{NH}_{2}\right.$ and $\left.-\mathrm{OH}\right)$ of $\mathbf{1}_{\mathbf{x}}$ absorb the UV-visible region light more than electron withdrawing groups $(\mathrm{X}=$ $-\mathrm{NO}_{2},-\mathrm{CN},-\mathrm{CONH}_{2}$ and $\left.-\mathrm{CO}_{2} \mathrm{H}\right)$. The red shifts of the UVvisible absorption bands to the visible spectrum region through the electron withdrawing substituents are in the following order: $1_{\mathrm{NO}_{2}}>1_{\mathrm{CONH}_{2}}>1_{\mathrm{CN}}>1_{\mathrm{H}}$. The red shifts of the UV-visible absorption bands to the visible spectrum region through the electron donating substituents are in the following order: $1_{\mathrm{NH}_{2}}$ $>1_{\mathrm{OH}}>1_{\mathrm{H}}$. The most efficiency of the UV-visible absorption among the substituents were belonged to $1_{\mathrm{NH}_{2}}$. At last, when both the electron donating and electron withdrawing substituents were attached at two sides of double bonds $\mathrm{C}_{2}=\mathrm{C}_{3}$ and $\mathrm{C}_{5}=\mathrm{C}_{6}$, absorb the visible region light more than the electron donating or electron withdrawing substituents. The red shifts of solar absorption bands to the visible spectrum region through the electron withdrawing-electron donating substituents were

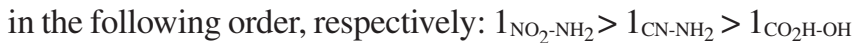
$>1_{\mathrm{CONH}_{2}-\mathrm{OH}}$. The solar absorption bands of $\mathbf{1}_{\mathbf{x}}$, shifted to the visible spectrum region, was mainly ascribed to the possibility of extention of conjugation of $\mathrm{C}=\mathrm{C}$ by the attached substituents.

\section{Conclusion}

The effects of both electron withdrawing and electron donating subsituents are investigated on various positions of $\mathbf{1}_{\mathbf{X}}$ and $\mathbf{2}_{\mathbf{X}}$. The electron donating and electrons withdrawing substituents of $\mathbf{1}_{\mathbf{x}}$, attached at $\mathrm{C}_{2}$, were suitable for the UVvisible absorption. The DFT calculations indicate that the solar absorption bands of $\mathbf{1}_{\mathbf{X}}$ were shifted to the visible spectrum region through the electron withdrawing substituents more than through electron donating substituents.

\section{ACKNOWLEDGEMENTS}

Islamic Azad University, Tabriz Branch is gratefully acknowledged due to their financial support of this research.

\section{REFERENCES}

1. R. Marzio, S. Antonio, F. Federico and F. Carlo, Inorg. Chem., 38, 1520 (1999).

2. A.D. Dubonosov, V.A. Bren and V.A. Chernoivnov, Russian Chem. Rev., 71, 917 (2002).

3. M.Z. Kassaee and E. Vessally, J. Mol. Struct. (Theochem.), 716, 159 (2005).

4. M.Z. Kassaee, E. Vessally and S. Arshadi, J. Mol. Struct. (Theochem.), 7636, 13 (2006).

5. (a) E. Vessally, Russ. J. Phys. Chem., 83, 809 (2009); (b) E. Vessally, Phosphorus, Sulfur Silicon Rel. Elem., 184, 2307 (2009).

6. (a) E. Vessally, J. Iran. Chem. Soc., 6, 99 (2009); (b) E. Vessally, M. Nikoorazm, A. Esmaili and H.G. Afshar, Russ. J. Phys. Chem., 85, 631 (2011).

7. C. Lee, W. Yang and R.G. Parr, Phys. Rev. B, 37, 785 (1988).

8. A.D. Becke, J. Chem. Phys., 98, 5648 (1993).

9. M.J. Frisch, et al., Gaussian 98, Revision A. 6, Gaussian Inc., Pittsburgh PA (1998). 